\title{
Bone marrow mesenchymal stem cells attenuate the progression of focal segmental glomerulosclerosis in rat models
}

\author{
Ru-chun Yang, Xiao-ling Zhu*, Jun Wang, Feng Wan, Hua-qin Zhang, Yi Lin, Xuan-li Tang and Bin Zhu
}

\begin{abstract}
Background: Focal segmental glomerulosclerosis (FSGS) is the most common glomerular etiology of end-stage kidney disease (ESKD). Increasing evidence has indicated the reparative potential of mesenchymal stem cells (MSCs) in damaged diseased kidneys. However, the effect of bone marrow mesenchymal stem cells (BMSCs) on the FSGS progression remains unclear. This study aimed to investigate the protective effects of BMSCs on FSGS progression.

Methods: A rat model of FSGS was generated via unilateral nephrectomy plus adriamycin injection. Rat BMSCs were isolated and characterized on the basis of their differentiative potential towards adipocytes and osteoblasts and via flow cytometry analysis. Thereafter, rat BMSCs were transplanted into FSGS recipients through the caudal vein. After 8 weeks, 24-h proteinuria, serum creatinine, and urea nitrogen levels were determined. Renal morphology was assessed using a light and transmission electron microscope. MMP9 and TIMP-1 positive cells were detected via immunohistochemical analysis. Expression levels of proinflammatory cytokines IL-6 and TNF-a were examined via RT-PCR.

Results: The isolated adherent cells from the bone marrow of rats were phenotypically and functionally equivalent to typical MSCs. Clinical examination revealed that BMSC transplantation reduced the 24-h urinary protein excretion, and serum creatinine and urea nitrogen levels. Renal morphology was ameliorated in BMSCs-transplanted rats. Mechanistically, BMSC transplantation significantly downregulated TIMP-1 and upregulated MMP9, thereby increasing the renal MMP9/ TIMP-1 ratio. Moreover, BMSC transplantation also downregulated IL-6 and TNF-a.

Conclusions: BMSC transplantation can attenuate FSGS progression in a rat model of FSGS, thereby providing a theoretical foundation for the application of autologous BMSCs in clinical FSGS therapy.
\end{abstract}

Keywords: BMSC, FSGS, MMP9/TIMP-1, Proinflammatory cytokines, Rat

\section{Background}

Focal segmental glomerulosclerosis (FSGS) is a heterogeneous disease affecting glomeruli, causing serious scarring $[1,2]$. The primary pathological features of FSGS include focal and segmented sclerosis, with proteinuria being the clinical manifestation [3]. FSGS develops rapidly and leads to progressive loss of kidney function. Once the condition becomes uncontrolledable, it may develop into renal failure within 1-2 years, accounting for $\sim 15 \%$ of cases of end-stage renal disease (ESRD) [4]. Current methods for FSGS treatment primarily rely on

\footnotetext{
* Correspondence: zhuxiaolinghz@126.com

Departmgent of Nephrology (Key laboratory of Zhejiang province, management of kidney disease), Hangzhou Hospital of Traditional Chinese Medicine, Tiyuchang Road 453, Hangzhou 310007, People's Republic of China
}

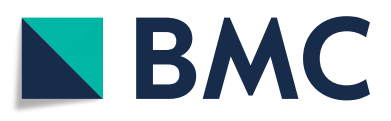

(c) The Author(s). 2018 Open Access This article is distributed under the terms of the Creative Commons Attribution 4.0 International License (http://creativecommons.org/licenses/by/4.0/), which permits unrestricted use, distribution, and reproduction in any medium, provided you give appropriate credit to the original author(s) and the source, provide a link to the Creative Commons license, and indicate if changes were made. The Creative Commons Public Domain Dedication waiver (http://creativecommons.org/publicdomain/zero/1.0/) applies to the data made available in this article, unless otherwise stated. ical curative effects are not durable owing to hormone resistance, which occurs in numerous patients [6]. Therefore, it is urgent to develop new treatments for controlling FSGS progression.

Mesenchymal stem cells (MSCs) are connective tissues progenitors, which have emerged as important tools for tissue engineering owing to their multi-potentiality, immune regulation, and multi-factor secretory function [7-10]. In recent years, increasing evidence has indicated the therapeutic potential of MSCs in treating nephropathy [11-14]. Transplantation of bone marrow stem cells (BMSCs) may contribute to glomerular regeneration and repair $[15,16]$. In addition, immunosuppression and paracrine function provide insights into the 
application of MSCs in tissue repair [17, 18]. Briefly, MSCs are anticipated to provide novel insights into FSGS treatment.

This study aimed to investigate the protective effects of BMSCs on FSGS progression in a rat model of FSGS established via unilateral nephrectomy and adriamycin administration. Our results may provide a theoretical basis for the clinical application of MSCs in renal therapeutic interventions.

\section{Methods}

\section{Animals}

Forty clean-grade male Sprague Dawley rats (weighing $160 \sim 180 \mathrm{~g}$ ) were purchased from the laboratory animal center of Zhejiang Chinese Medicine University. The rats were housed under standard conditions, as described previously [19]. Animal experiments were performed in accordance with local guidelines for the care of laboratory animals of Animal Experimental Center and were approved by the ethics committee for research on laboratory animal use of the Zhejiang Chinese Medical University.

\section{Establishment of the FSGS model}

All rats were allowed to acclimatize for a week and weighed and assigned randomly to three groups $(n=$ 10 rats/group). The rat number was statistics calculated by our preliminary experimental results based on the proteinuria difference between control and model group. To establish the FSGS model, the rats were first subjected to unilateral nephrectomy (left side) on day 1 and then injected $5 \mathrm{mg} / \mathrm{kg}$ (on day 7) and $3 \mathrm{mg} / \mathrm{kg}$ (on day 28) of adriamycin, dissolved in $0.9 \%$ saline at a dilution of $2 \mathrm{mg} / \mathrm{mL}$, in the caudal vein [20]. Meanwhile, the kidneys of the control rats were exposed without dissecting the kidney tissue, followed by layer-by-layer suturing. These rats were then injected saline on day 7 and day 28 through the tail vein after sham operation. Eight weeks post-surgery, the serum and whole kidneys were harvested for biochemical, histological, and molecular analyses, and then animals were euthanized by dislocation of the cervical spine. The urinary protein levels of the rats were quantified before the end of the experiment.

\section{Isolation and culture of rat BMSCs}

Rat BMSCs were isolated in accordance with a previously reported method [21]. Briefly, the cells obtained from the bone marrow were cultured in Iscove's Modified Dulbecco's Medium (IMDM; Sigma), supplemented with $10 \%$ fetal bovine serum (Hyclone, Rockville, MD, USA), $100 \mathrm{U} / \mathrm{mL}$ of penicillin (Gibco BRL, Rockville, MD, USA) and $100 \mathrm{mg} / \mathrm{mL}$ streptomycin (Gibco BRL) at $37^{\circ} \mathrm{C}$ in $5 \% \mathrm{CO}_{2}$. After $3 \mathrm{~d}$, non-adherent cells and debris were eliminated, and adherent cells were cultured continuously. Upon attaining $\sim 90 \%$ confluence, cells were digested using $0.25 \%$ trypsin-EDTA (Sigma) and then seeded into glass flasks at a cell density of $4 \times 10^{4}$ per $\mathrm{cm}^{2}$ as the first passage. The third and fifth passages cells (P3P5) were used for functional characterization and phenotype analysis. The cultures were maintained by changing the medium every 3 days.

\section{Characterization of rat BMSCs \\ Differentiation}

The cells were characterized on the basis of their mesenchymal lineage differentiation potentials as described previously [22]. For osteogenic differentiation, cells were cultured in IMDM, supplemented with $10 \mathrm{mM} \beta$-glycerophosphate, $50 \mathrm{mg} / \mathrm{mL}$ ascorbic acid (Sigma), and $10^{-}$ ${ }^{7} \mathrm{M}$ dexamethasone (Dex), and incubated for $21 \mathrm{~d}$. The differentiated cells were then stained with fresh $0.5 \%$ Alizarin Red. Adipogenic differentiation was induced using an adipocyte-inductive medium (IMDM supplemented with $50 \mu \mathrm{g} / \mathrm{mL}$ insulin and $10^{-7} \mathrm{M}$ Dex). Thereafter, the intracellular lipid droplets were stained with fresh oil Red-O.

\section{Flow cytometry (FCM) analysis}

The single cell suspension was prepared from the P3-P5 rat BMSCs. After fixing tissues in 4\% paraformaldehyde for $15 \mathrm{~min}$, the cells were blocked with 5\% normal goat serum for $1 \mathrm{~h}$ at $4{ }^{\circ} \mathrm{C}$ and incubated with fluorescein-labeled antibodies, including anti-CD29, anti-CD90, anti-MHC-II, and anti-CD45 antibodies. The nonspecific mouse or rabbit IgG served as an isotype control. Afterward, fluorescence signals were determined using a Cytomics FC500 MPL flow cytometer (Beckman Coulter, USA) at $488 \mathrm{~nm}$.

\section{BMSC transplantation}

$1 \times 10^{7} / \mathrm{mL}$ rat BMSCs were transplanted into FSGS recipients through the caudal vein on days 28 and 42, as described previously [23]. Before euthanasia, animals were housed in metabolic cages to collect 24-h urine samples for analysis of urinary protein excretion. Thereafter, the kidneys were harvested for histological analysis and detection of MMP9, TIMP-1, and inflammatory factors. Meanwhile, serums samples were isolated to detect the levels of creatinine and urea nitrogen.

\section{Histological analysis}

Kidney tissues were fixed with $4 \%$ paraformaldehyde and embedded in paraffin. For histological analysis of lesions, $3 \mu \mathrm{m}$-thick tissue sections were deparaffinized and stained with hematoxylin and eosin (HE) and 
Table 1 Primers used for gene expression analyses

\begin{tabular}{lll}
\hline Primer Name & Sequence $\left(\right.$ ( $^{\prime}$ to 3 $^{\prime}$ ) & Application \\
\hline Rat-IL-6-F & CCTTCTTGGGACTGATGT & Real-time RT-PCR \\
Rat-IL-6-R & TCCAGGTAGAAACGGAAC & Real-time RT-PCR \\
Rat-TNF-a-F & GGCGTGTTCATCCGTCT & Real-time RT-PCR \\
Rat-TNF-a-R & CCACTACTTCAGCGTCTCG & Real-time RT-PCR \\
Rat-GAPDH-F & ACCACAGTCCATGCCATCAC & Real-time RT-PCR \\
Rat-GAPDH-R & TCCACCACCCTGTTGCTGTA & Real-time RT-PCR \\
\hline
\end{tabular}

periodic acid-Schiff (PAS). To calculate focal glomerular sclerosis, 40 to 60 glomeruli from each stained specimen were examined. The degree of sclerosis in each glomerulus was subjectively graded on a scale of 0 to 4 as follows: Grade 0, no change; Grade 1, sclerotic area less than or equal to $25 \%$ of the glomerulus or the presence of distinct adhesion between the capillary tuft and Bowman's capsule; Grade 2, sclerosis of 25 to $50 \%$ of the total glomerular area; Grade 3, sclerosis of 50 to $75 \%$ of the total glomerular area; and Grade 4, sclerosis of more than $75 \%$ of the glomerulus. The glomerular sclerosis index (GSI) was calculated by using the following formula as previously reported [24]:

GSI $=\frac{(1 \times \mathrm{N} 1)+(2 \times \mathrm{N} 2)+(3 \times \mathrm{N} 3)+(4 \times \mathrm{N} 4)}{(\mathrm{N} 0+\mathrm{N} 1+\mathrm{N} 2+\mathrm{N} 3+\mathrm{N} 4)}$, where $\mathrm{N}$ is the number of glomeruli at each grade of sclerosis.

For immunohistochemistry, paraffin-embedded kidney sections were blocked with $5 \%$ goat serum at $37^{\circ} \mathrm{C}$ for $1 \mathrm{~h}$, and then stained with anti-MMP-9 and anti-TIMP-1 antibodies (1:500 and 1:50, respectively; Boster Biological
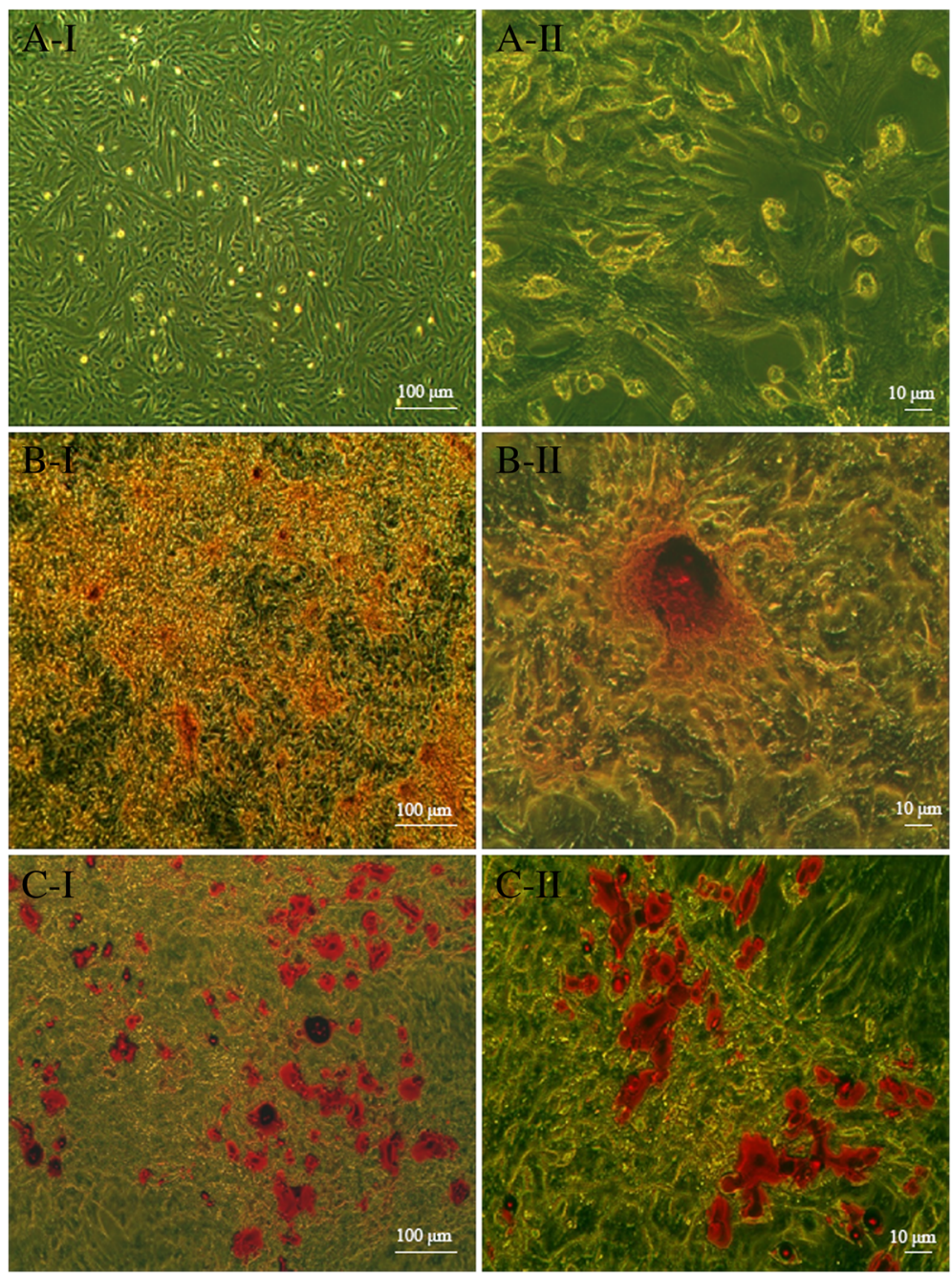

Fig. 1 Characterization of rat BMSCs. a Morphological observation of the adherent P3 cells under an inverted microscope. b Adipogenic differentiation of BMSCs: BMSCs were cultured for $21 \mathrm{~d}$ alternately in adipogenic induction medium. Lipid droplets were visualized by Oil Red O staining. c Osteogenic differentiation of BMSCs: cells were cultured for $21 \mathrm{~d}$ with osteogenic induction medium, and calcium deposits were visualized by Alizarin Red staining. a-c I: original magnification $\times 40$; a-c: II, original magnification $\times 200$ 
Technology Co., Ltd., Wuhan) in accordance with the manufacturers' instructions. Thereafter, kidney tissues were incubated with HRP-conjugated anti-rabbit/mouse IgG Ab $(1,8000)$ at $37^{\circ} \mathrm{C}$ for $1 \mathrm{~h}$. Finally, the slides were incubated with $\mathrm{DAB}$ peroxidase substrate (Sigma). The staining results were obtained via light microscope (Olympus BX51).
Transmission electron microscopy (TEM)

After fixation in $2.5 \%$ glutaraldehyde for at least $3 \mathrm{~h}$, the kidney tissue $\left(\sim 1 \mathrm{~mm}^{3}\right.$ in size) was rinsed in $0.1 \mathrm{M} \mathrm{PBS}$ thrice, post-fixed with $1 \%$ osmium tetroxide for $1 \mathrm{~h}$, dehydrated in graded acetone and embedded in graded Epon 812. Thin sections $(80-100 \mathrm{~nm})$ were cut and
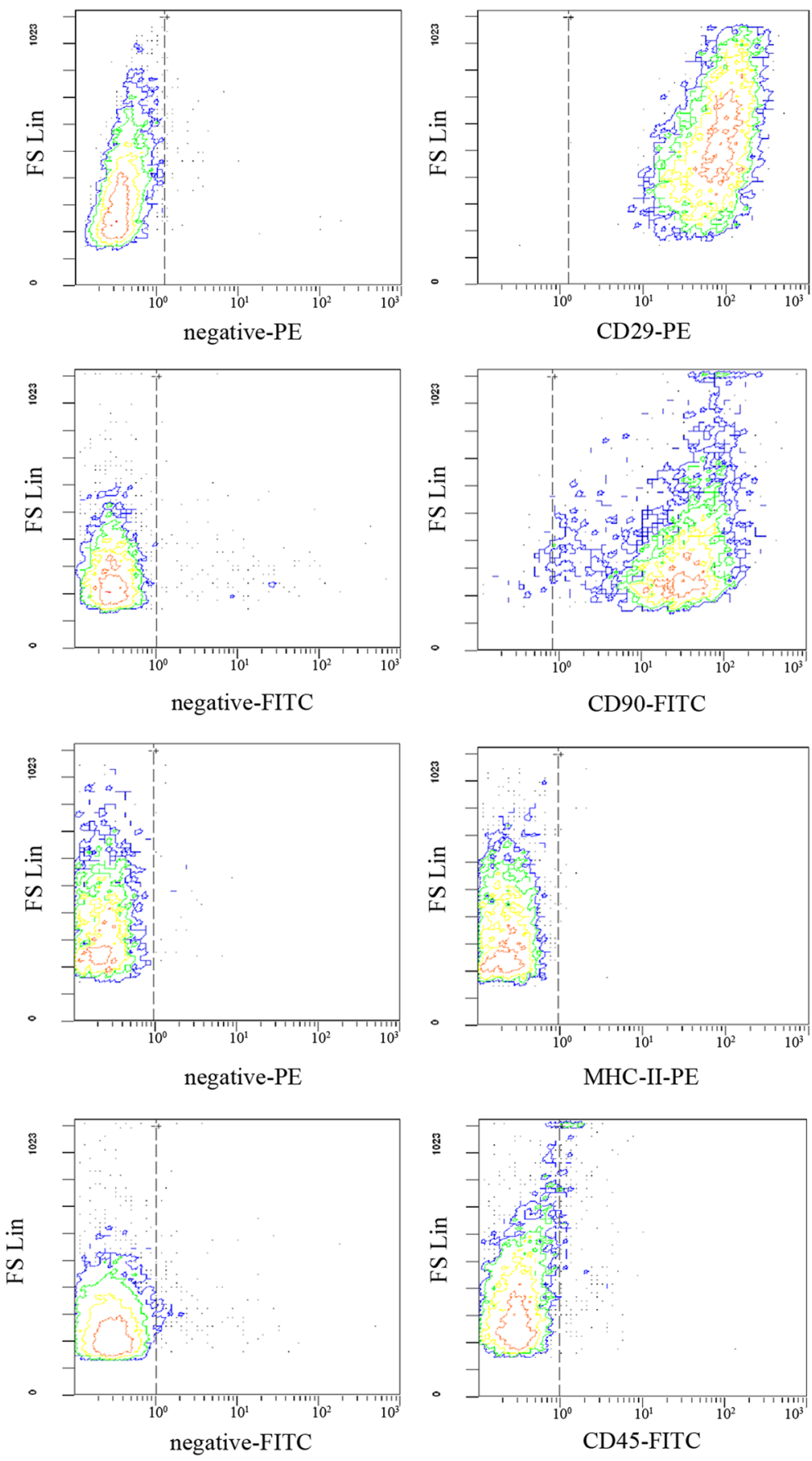

Fig. 2 Immunophenotypic analyse of BMSCs by FCM. Single cell suspensions of BMSCs were stained with CD29, CD90, MHC-II, and CD45, respectively. Unrelated IgG was used as negative control 
stained with uranyl acetate (2\%) and lead citrate before observation under a JEM-1400 transmission electron microscope (JEOL, Japan).

\section{Real-time quantitative PCR}

Total RNA was extracted from kidney tissue using TRIzol reagent (Invitrogen, USA) and was reverse-transcribed to cDNA, using a PrimescriptTM RT reagent kit (TaKaRa, China). Thereafter, expression levels of IL- 6 and TNF- $\alpha$ were quantified via real-time PCR using Applied Biosystems 7500 Fast real-time PCR system (Thermo Fisher Scientific, USA) and detection system software, using primers shown in Table 1. Relative mRNA expression levels were normalized to those of GAPDH via the $2^{-\Delta \Delta C T}$ method. Each PCR experiment was performed in triplicate and repeated independently at least thrice.

\section{Statistical analysis}

All values are presented as the mean $\pm S D$ values. The data shown were analyzed for significance via Student's $t$-tests or One-Way ANOVA using SPSS17.0 software. A $p$-value less than 0.05 or 0.01 indicated statistical significance. Besides, the investigators for group allocation and data analysis in our experiments were both blinded.

\section{Results}

\section{Isolation and characterization of rat BMSCs}

Rat BMSCs were harvested, purified, and cultured in vitro. Majority of the isolated cells displayed spindle-like morphology. After more than 3 passages in culture, they tended to be morphologically more heterogeneous (Fig. 1a). For further identification, the mesodermal differentiation potential of these cells was evaluated. The cells were induced to differentiate into adipocytes and osteocytes in vitro, using adipogenic and oseteogenic induction media, respectively. Following 3 weeks of adipogenic induction, these cells exhibited lipid-laden adipocyte phenotype, indicated by a positive result on Oil Red 'O' staining (Fig. 1b). Similarly, when induced with osteogenic induction medium for 2 to 3 weeks, they also displayed osteogenesis upon staining with
Alizarin Red for calcium deposits (Fig. 1c). Finally, flow cytometry analysis was performed to analyze the phenotypic characteristics of the isolated cells. The isolated cells were CD29- and CD90-positive, and negative for MHC-II and CD45 (Fig. 2). Collectively, these results strongly indicate that the isolated adherent cells were phenotypically and functionally equivalent to typical MSCs.

\section{BMSC transplantation reduced urinary protein excretion of FSGS rats}

Through unilateral nephrectomy plus adriamycin injection, the FSGS rat model was successfully established, which subsequently lead to the emergence of increased proteinuria after 6 weeks (Fig. 3, $p<0.01$ ), as a typical clinical feature of FSGS. Meanwhile, the serum albumin (ALB) in the model group decreased significantly compared with the control group (Fig. 3, $p<0.01$ ). Although the ALB level has no obvious improvement, the 24-h urinary protein excretion in BMSC-treated group of rats was much lower than in the model group at 6 weeks (Fig. 3, $p$ $<0.05$ ), indicating the attenuation of renal injury progression to some extent by BMSC transplantation.

\section{BMSC transplantation improve the kidney function of FSGS rats}

To evaluate renal dysfunction, changes in serum creatinine (Scr) and urea nitrogen (BUN) were initially examined. Results showed that while the control rats had normal levels of Scr $(32.6 \pm 2.88 \mu \mathrm{mol} / \mathrm{L})$ and BUN $(5.9 \pm 0.89 \mathrm{mmol} / \mathrm{L})$, the model group had increased levels of both $(68.7 \pm 14.38 \mu \mathrm{mol} / \mathrm{L}$ and 10.65 $\pm 1.88 \mathrm{mmol} / \mathrm{L}$, respectively; Fig. $4, p<0.01$ ). Compared to that in the model group, Scr and BUN levels in BMSC transplantation group were significantly lower $(52.9 \pm 4.95 \mu \mathrm{mol} / \mathrm{L}$ and $7.19 \pm 1.03 \mathrm{mmol} / \mathrm{L}$, respectively, $p<0.01$ ). Meanwhile, the cholesterol (TC) and triglycerides (TG) levels were also examined. Expectedly, they showed similar tendency with that of Scr and BUN (Fig. 4). These results suggested that BMSC treatment could improve kidney function.
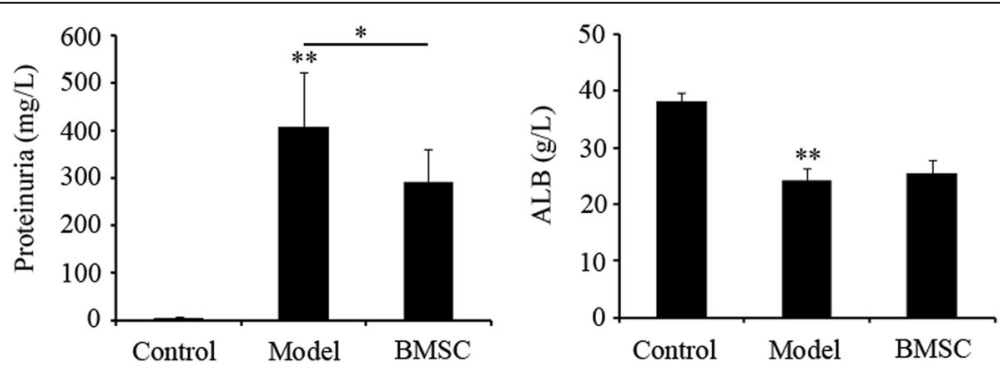

Fig. 3 Evaluation of proteinuria concentration. Twenty four-hour urine was collected from rats of control, model and BMSC-treated groups (Control, Model, and BMSC), and total urinary protein was measured by a chemistry analyzer (HITACH 7180). Data $(n=10)$ are presented as the mean $\pm S D,{ }^{*} p<0.05$, vs. BMSC and model groups; ${ }^{* *} p<0.01$, vs. model and control groups 

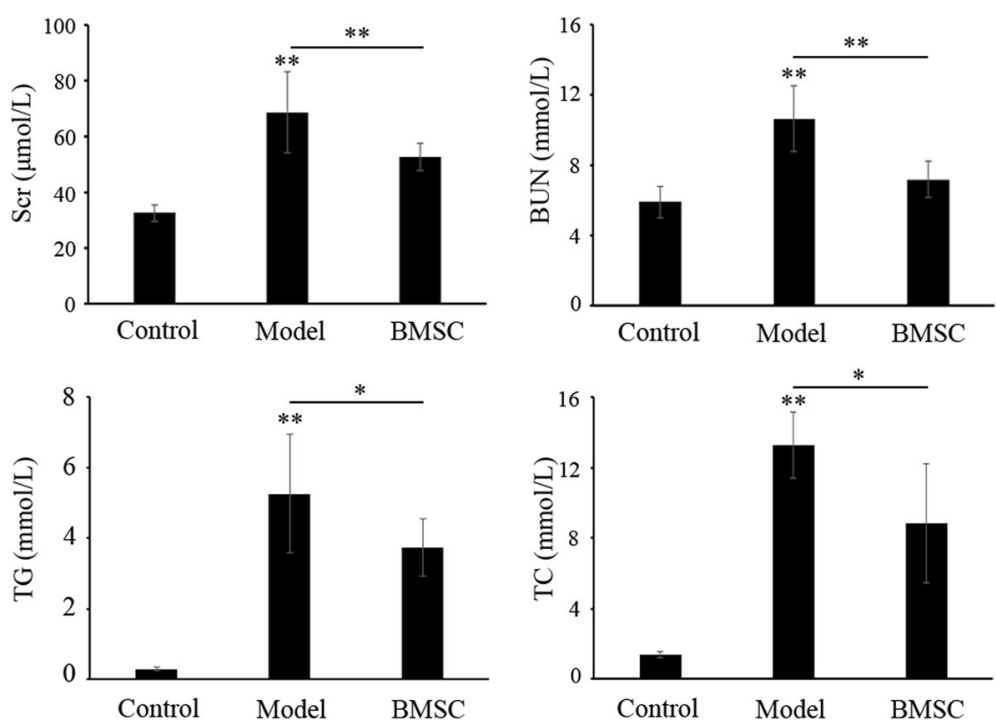

Fig. 4 Evaluation of serum creatinine and urea nitrogen concentration. Serum creatinine and urea nitrogen were collected and measured by a chemistry analyzer (HITACHI 7180). Data $(n=10)$ are presented as the mean \pm SD, ${ }^{* *} p<0.01$

\section{BMSC transplantation affected renal morphology}

Pathological lesions in the kidney tissues were further examined by histological analysis. Light microscopy results of $\mathrm{HE}$ and PAS staining showed obvious pathological changes in rat kidneys from the model group, characterized by focal glomerular sclerosis in some glomerular and interstitial lesion (Fig. 5). In the BMSC-treated group, such pathological damages were much less compared to that in the model group, whereas no pathological change was found in kidneys from the control group (Fig. 5). Correspondingly, the glomerular sclerosis index (GSI) was higher in the

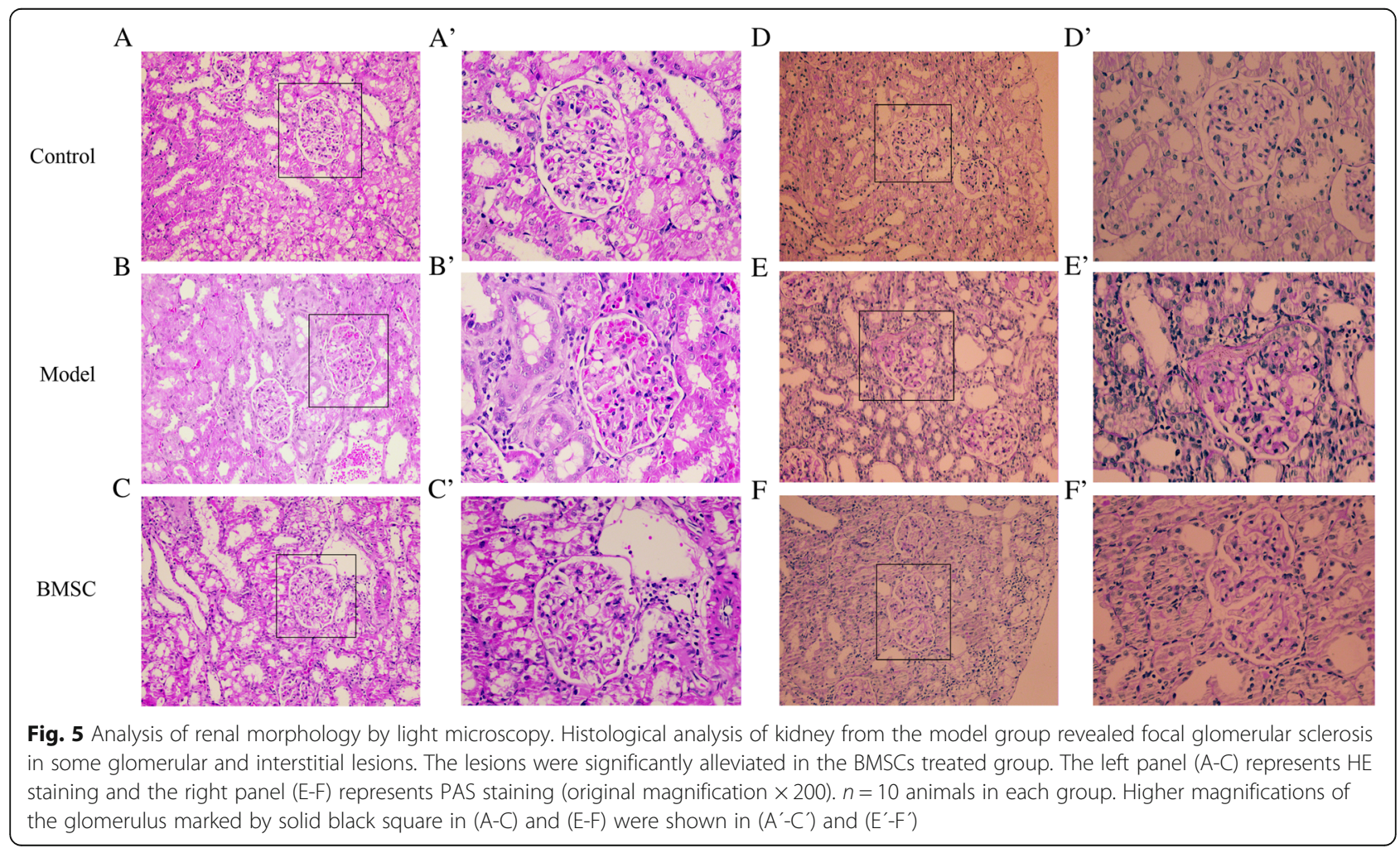




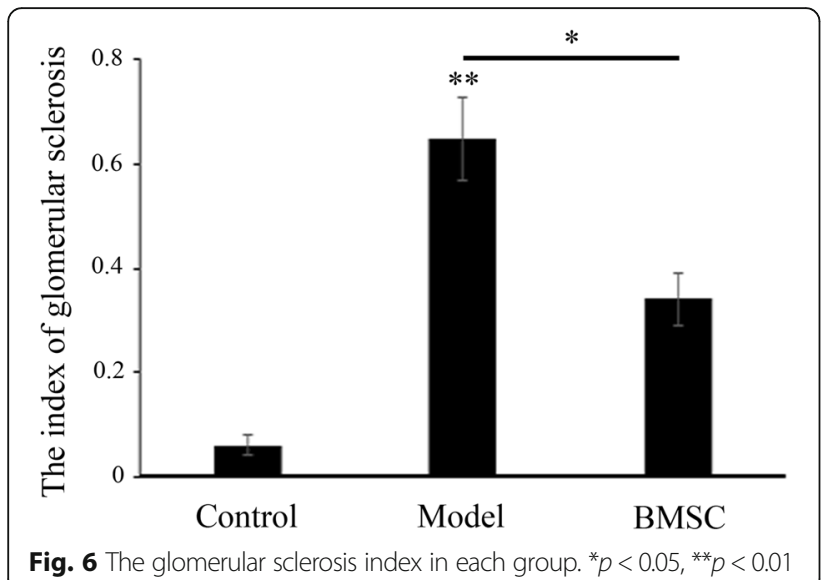

model group than that of the control group (Fig. $6, p<$ 0.01). However, the BMSC-treated group significantly decreased the GSI compared to that in the model group (Fig. $6, p<0.05$ ).

Correspondingly, TEM analysis showed intact glomeruli and clear foot processes on the visceral surface of the renal glomerular epithelial cells in the control rats. However, the foot processes diffusely effaced, became flat and fused and even disappeared in the model group (Fig. 7). The foot process fusion rate $(88 \% \pm 7.55 \%)$ increased in the model group compared with the control group $(5.2 \% \pm 3.11 \%)$. Besides, the glomerular basement membrane was thickened and collapsed (Fig. 7). In the BMSC-treated group, the lesions were significantly alleviated and the foot fusion rate reduced compared with the model group $(69 \% \pm$ 7.94\%). These results indicated BMSC transplantation can improve renal morphology.

\section{BMSC transplantation improved the renal MMP/TIMP imbalance}

Matrix metalloproteinases (MMPs) are reported as important markers of deleterious remodeling associated with the progression of renal diseases [25]. The relative balance between MMP and its tissue inhibitor TIMP is considered to determine the rate of extracellular matrix (ECM) turnover. Therefore, we evaluated the expression of MMP9 and TIMP-1 in rats from different groups. Immunohistochemical results showed MMP9 to be abundant in renal tubule and TIMP-1 mainly localized to the renal tubular epithelium, interstitium, and glomerular mesangial region (Fig. 8a). Moreover, RT-PCR results indicated the mRNA expression level of MMP9 and TIMP-1 were both much higher than that in the control group (Fig. $8 \mathrm{~b}, p<0.01$ or $p<0.05$ ), resulting the MMP9/TIMP-1 ratio decreased significantly (Fig. $8 \mathrm{c}, p$ $<0.01$ ). Compared to that in the model group, BMSC transplantation significantly decreased MMP9 and TIMP-1 expression (Fig. 8b, $p<0.01$ ). Besides, renal MMP9/TIMP-1 ratio was also elevated, which may lead to the decrease in ECM accumulation. Taken together,

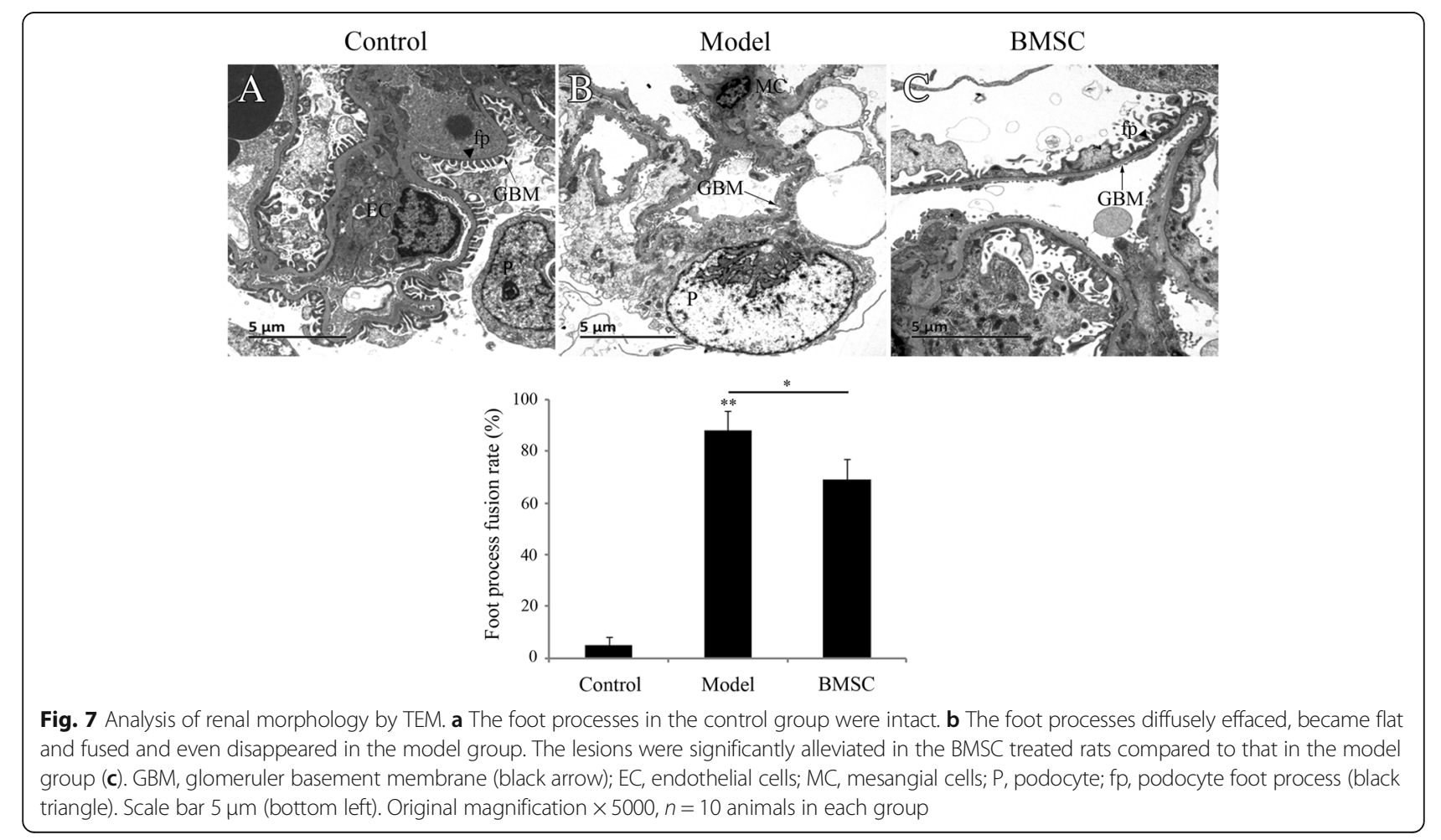




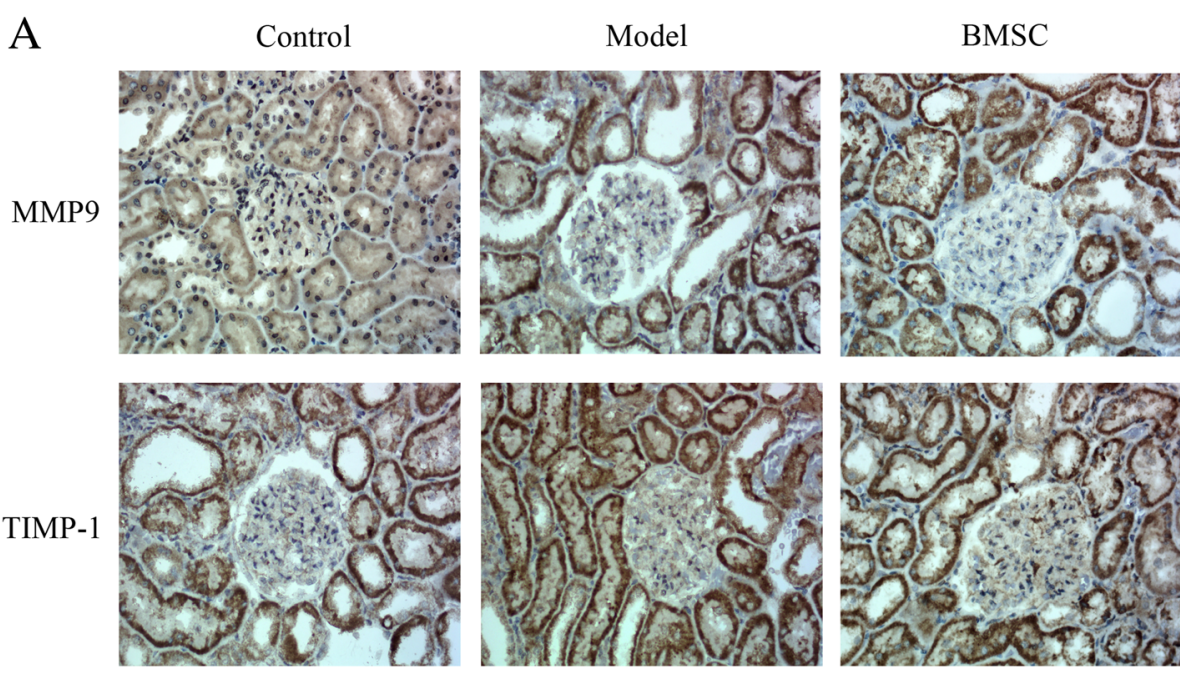

B

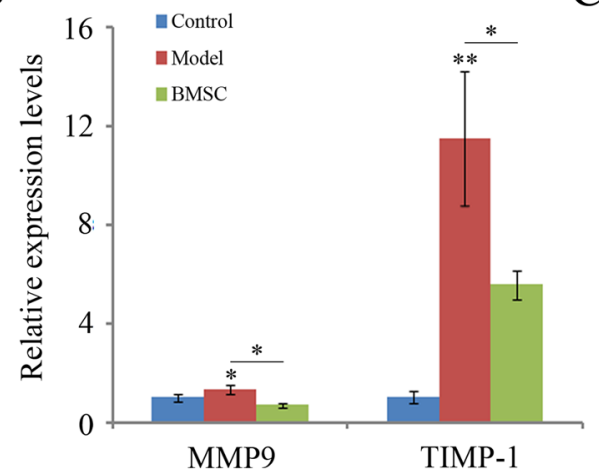

$\mathrm{C}$

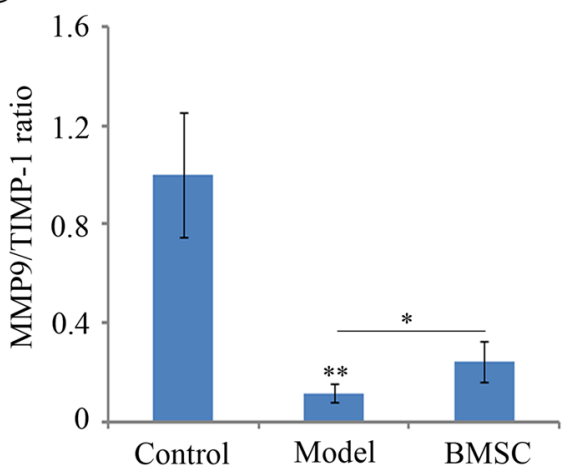

Fig. 8 Immunohistochemical analyse of renal MMP9 and TIMP-1. a Paraffin sections of kidney from control, model and BMSC-treated groups (Control, Model and BMSC respectively) were stained with MMP9 and TIMP-1. The staining results were observed under a light microscope, original magnification $\times 400$. $\mathbf{b}$ The expression of MMP9 and TIMP-1 were determined by RT-PCR. Quantitative data are provided as the mean \pm SD. ${ }^{*} p<0.05,{ }^{* *} p<0.01$. c The MMP9/TIMP-1 ratio was further calculated. The statistical data $(n=10)$ are given as the mean \pm SD, ${ }^{* *} p<$ $0.01,{ }^{*} p<0.05$

these results suggested that BMSC transplantation may improve renal MMP/TIMP-1 imbalance.

\section{BMSC transplantation suppressed the expression of renal inflammatory factors in FSGS rats}

Considering the pathogenic role of inflammation in the development of renal fibrosis, expression of several important inflammatory factors were further evaluated in our study. We found that expression of IL- 6 and TNF- $\alpha$ remarkably increased in the model group compared to that in the control group. However, the expression decreased significantly in BMSC-treated group, indicating inflammatory inhibition upon BMSC transplantation (Fig. 9).

\section{Discussion}

FSGS was first described in kidney biopsy of adults with nephritic syndrome in 1925 [26]. It has since been considered a lesion, rather than a disease, with morphologic variations including tip, perihilar, cellular, collapsing, and

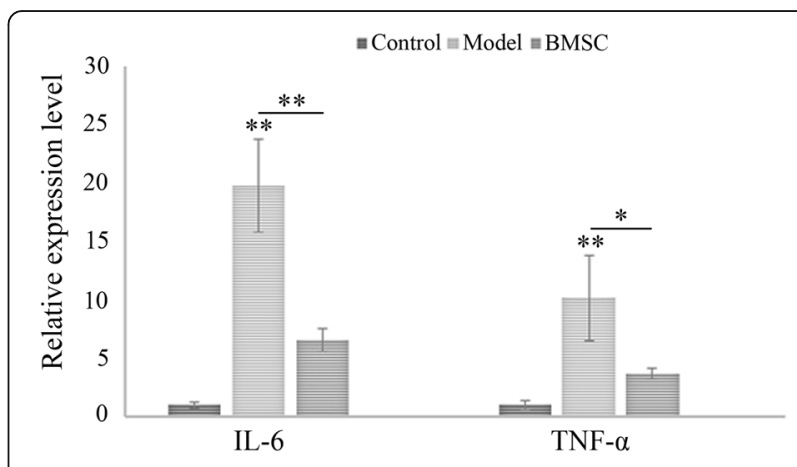

Fig. 9 Analysis of the expression of renal inflammatory factors by RTPCR. Transcription of inflammatory factors, including IL-6 and TNF- $a$ was detected by RT-PCR, and mRNA expression levels were normalized to that of GAPDH. Quantitative data $(n=10)$ are provided as the mean $\pm \mathrm{SD} .{ }^{*} p<0.05,{ }^{* *} p<0.01$ 
not-otherwise-specified features [27]. FSGS is a clinicopathologic entity that is characterized frequently by steroid-resistant nephrotic syndrome and rapid progression to end-stage kidney disease (ESKD) in majority of affected individuals [4]. The therapeutic agents, currently available for the treatment of FSGS, are not very effective and only few patients have shown complete remission. Therefore, to seek a safer and more effective method to revert FSGS progression is an imminent challenge.

In recent years, positive effects of MSCs on different models of chronic kidney diseases have been reported, mainly as improvements in proteinuria, glomerulosclerosis, macrophage infiltration, renal fibrosis, renal filtration, and plasma creatinine [12, 14, 28-31]. In our present study, the effect of BMSCs on FSGS was evaluated by a series of assays in a rat model. Adriamycin nephropathy is a common kidney disease model, that resembles FSGS in its chronic phase [20]. Our study found that unilateral nephrectomy and adriamycin injection in rats had massive proteinuria after 6 weeks, hence coinciding with the clinical manifestations of FSGS. Biochemical and histological changes suggested that adriamycin nephropathy was successfully established in our experimental preparation. After BMSC transplantation, the progression of FSGS was prevented. Initially, 24-h urinary protein excretion decreased significantly in BMSC-treated group of rats, indicating attenuation of renal injury progression by BMSC transplantation. Biochemical analysis results showed that the rats with BMSC transplantation had much lower serum creatinine and urea nitrogen levels, which in turn suggested recovery of the injured renal function. Immunohistochemical and RT-PCR results showed increase of MMP9 and decrease of its tissue inhibitor TIMP-1, thereby leading to an enhanced ratio of MMP/TIMP and hence degradation of extracellular matrix (ECM), which may be important for preventing renal fibrosis. Finally, our study found renal IL- 6 and TNF- $\alpha$ to be much higher in the model group than in the control group, hence suggesting accompanied by inflammatory responses in the FSGS rat. When the BMSCs were transplanted, the expression levels of these inflammatory factors were suppressed. Based on previous studies, we speculated that BMSC transplantation may attenuate the progression of FSGS by immune-regulation.

Taken together, we present the results of a preliminary study of application of BMSCs on FSGS treatment in a rat model. The beneficial effect of BMSCs might be mediated by increasing the MMP/TIMP ratio, and down-regulating the pro-inflammatory cytokines to decrease inflammatory cell infiltration in the renal interstitium. Our study provides an experimental basis for application of BMSC therapy in renal diseases. However, the underlying mechanisms for BMSCs in FSGS need to be addressed in future.

\section{Conclusions}

We established the FSGS rat model through unilateral nephrectomy and adriamycin injection, and investigated the effect of BMSCs on FSGS treatment in this paper. The main indices include 24-h urinary protein, serum creatinine, urea nitrogen, and renal morphology. In terms of mechanism, BMSCs may relieve FSGS by improving the imbalance of renal MMP/TIMP and suppressing the expression of renal inflammatory factors IL- 6 and TNF- $\alpha$. The precise mechanism involved is still under investigation.

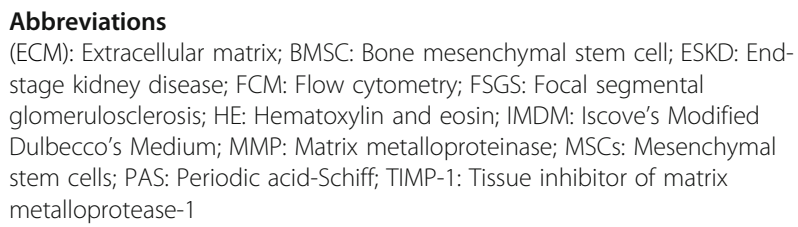

\section{Funding}

This work was supported by grants from the National Natural Science Foundation of China (81173426), Zhejiang Natural Science Foundation of China (LY15H050006) and Hangzhou science and Technology Bureau (20160533B60). The funding bodies had no involvement in the design of the study and collection, analysis, interpretation of data and in writing the manuscript.

\section{Availability of data and materials}

The datasets used and analysed during the current study are available from the corresponding author on reasonable request.

\section{Authors' contributions}

RCY designed the study, conducted the animal experiments and drafted the manuscript. XLZ was responsible for financial support of the study, conceived and designed the study, and provided final supervision. JW and HQZ are mainly responsible for the animal experiments. FW performed cell culture studies, the creation of the figures, and revised the manuscript. $Y L$ participated in the biochemical analyses. XLT performed immunostaining and TEM. BZ provided efforts in gene expression and data analysis. All authors have approved the final version of the manuscript.

\section{Ethics approval and consent to participate}

All procedures and handing of animals in this study were performed according to local guidelines for the care of laboratory animals of Animal Experimental Center and were approved by the ethics committee for research on laboratory animal use of the Zhejiang Chinese Medical University.

Consent for publication Not applicable.

\section{Competing interests}

The authors declare that they have no competing interests.

\section{Publisher's Note}

Springer Nature remains neutral with regard to jurisdictional claims in published maps and institutional affiliations. 
Received: 30 October 2017 Accepted: 14 November 2018

Published online: 22 November 2018

\section{References}

1. Hossain MP, Goyder EC, Rigby JE, El Nahas M. CKD and poverty: a growing global challenge. Am J Kidney Dis. 2009;53(1):166-74.

2. Shan Y, Zhang Q, Liu Z, Hu X, Liu D. Prevalence and risk factors associated with chronic kidney disease in adults over 40 years: a population study from Central China. Nephrology. 2010;15(3):354.

3. Ying MC, Liapis H. Focal segmental glomerulosclerosis: molecular genetics and targeted therapies. BMC Nephrol. 2015;16(1):101.

4. Gbadegesin R, Lavin P, Foreman J, Winn M. Pathogenesis and therapy of focal segmental glomerulosclerosis: an update. Pediatr Nephrol. 2011; 26(7):1001-15

5. Belingheri M, Lazzari L, Parazzi V, Groppali E, Biagi E, Gaipa G, et al. Allogeneic mesenchymal stem cell infusion for the stabilization offocal segmental glomerulosclerosis. Biologicals. 2013;41(6):439.

6. Caldas HC, Hayashi AP, Abbud-Filho M. Repairing the chronic damaged kidney: the role of regenerative medicine. Transplant Proc. 2011;43(10): 3573-6.

7. $M F P, A M ~ M, S C B, R K J, R D$, JD M, et al. Multilineage potential of adult human mesenchymal stem cells. Science. 1999;284(5411):143-7.

8. De Miguel MP, Fuentesjulián S, Blázquezmartínez A, Pascual CY, Aller MA, Arias J, et al. Immunosuppressive properties of mesenchymal stem cells: advances and applications. Curr Mol Med. 2012;12(5):574

9. Yi T, Song SU. Immunomodulatory properties of mesenchymal stem cells and their therapeutic applications. Arch Pharm Res. 2012;35(2):213-21.

10. Zhao ZG, Sun L, Wang XF, Zhang YZ, Yu Y, Yang HL, et al. Immunomodulatory effects of mesenchymal stem cells derived from the bone marrow in acute leukemia patients. Zhonghua Zhong Liu Za Zhi. 2011;33(2):105-9.

11. Villanueva S, Ewertz E, Carrión F, Tapia A, Vergara C, Céspedes C, et al. Mesenchymal stem cell injection ameliorates chronic renal failure in a rat model. Clin Sci. 2011;121(11):489-99.

12. Choi S, Park M, Kim J, Hwang S, Park S, Lee Y. The role of mesenchymal stem cells in the functional improvement of chronic renal failure. Stem Cells Dev. 2009;18(3):521.

13. Choi SJ, Kim JK, Hwang SD. Mesenchymal stem cell therapy for chronic renal failure. Expert Opin Biol Ther. 2010;10(8):1217-26.

14. Moon JY. Repeated administration of bone marrow-derived mesenchymal stem cells improved the protective effects on a remnant kidney model. Ren Fail. 2010;32(7):840

15. Roufosse CA. The contribution of bone marrow stem cells to renal parenchymal regeneration [D]. London, Imperial College London (thesis: 435154), 2006

16. Ikarashi K, Bing LI, Suwa M, Kawamura K, Morioka T, Yao J, et al. Bone marrow cells contribute to regeneration of damaged glomerular endothelial cells. Kidney Int. 2005;67(5):1925-33.

17. Li Z, Guo J, Chang Q, Zhang A. Paracrine role for mesenchymal stem cells in acute myocardial infarction. Biol Pharm Bull. 2009;32(8):1343-6.

18. Djouad F, Plence P, Bony C, Tropel P, Apparailly F, Sany J, et al. Immunosuppressive effect of mesenchymal stem cells favors tumor growth in allogeneic animals. Blood. 2003;102(10):3837-44.

19. Li QY, Li F, Sun JH, Chi YY, Yin HS, Liu SQ, et al. Mechanisms of diabetes mellitus induced with FK506 in SD rats models. Immunopharmacol Immunotoxicol. 2009;31(4):675-81.

20. Lee WW, Harris DC. Adriamycin nephropathy: a model of focal segmental glomerulosclerosis. Nephrology. 2011;16(1):30.

21. Chen $Y$, Dong $X J$, Zhang GR, Shao JZ, Xiang $L X$. In vitro differentiation of mouse bone marrow stromal stem cells into hepatocytes induced by conditioned culture medium of hepatocytes. J Cell Biochem. 2007; 102(1):52-63.

22. Chen $Y$, Pan $R L$, Zhang $X L$, Shao JZ, Xiang LX, Dong XJ, et al. Induction of hepatic differentiation of mouse bone marrow stromal stem cells by the histone deacetylase inhibitor VPA. J Cell Mol Med. 2009;13(8b):2582.

23. Pan $R L$, Wang $P$, Xiang $L X$, Shao JZ. Delta-like 1 serves as a new target and contributor to liver fibrosis down-regulated by mesenchymal stem cell transplantation. J Biol Chem. 2011:286(14):12340-8.

24. Takata T, Munemura C, Fukui T, Fukuda S, Murawaki Y. Influence of Olmesartan on Sirtuin 1 mRNA expression in 5/6 Nephrectomized spontaneously hypertensive rats. Yonago Acta Medica. 2015;58(2):63-8.
25. Pulido-Olmo H, García-Prieto CF, Álvarez-Llamas G, Barderas MG, Vivanco $F$, Aranguez I, et al. Role of matrix metalloproteinase-9 in chronic kidney disease: a new biomarker of resistant albuminuria. Clin Sci. 2016; 130(7):525-38.

26. Weening JJ, Jennette JC. Historical milestones in renal pathology. Virchows Arch. 2012;461(1):3-11.

27. D'Agati VD, Kaskel FJ, Falk RJ. Focal Segmental Glomerulosclerosis - NEJM. Pediatr Nephrol. 2005;172(12):129.

28. Cavaglieri RC, Martini D, Sogayar MC, Noronha IL. Mesenchymal stem cells delivered at the subcapsule of the kidney ameliorate renal disease in the rat remnant kidney model. Transplant Proc. 2009;41(3):947-51.

29. Asanuma H, Vanderbrink BA, Campbell MT, Hile KL, Zhang H, Meldrum DR, et al. Arterially delivered mesenchymal stem cells prevent obstructioninduced renal fibrosis. J Surg Res. 2011;168(1):e51-9.

30. Ma H, Wu Y, Xu Y, Sun L, Zhang X. Human umbilical mesenchymal stem cells attenuate the progression of focal segmental glomerulosclerosis. Am J Med Sci. 2013;346(6):486.

31. Kelley R, Werdin ES, Bruce AT, Choudhury S, Wallace SM, llagan RM, et al. Tubular cell-enriched subpopulation of primary renal cells improves survival and augments kidney function in rodent model of chronic kidney disease. Am J Physiol Renal Physiol. 2010;299(5):F1026.

Ready to submit your research? Choose BMC and benefit from:

- fast, convenient online submission

- thorough peer review by experienced researchers in your field

- rapid publication on acceptance

- support for research data, including large and complex data types

- gold Open Access which fosters wider collaboration and increased citations

- maximum visibility for your research: over $100 \mathrm{M}$ website views per year

At $\mathrm{BMC}$, research is always in progress.

Learn more biomedcentral.com/submissions 